\title{
Evaluating Employee Performance using Automated Task Management System in Higher Educational Institutions
}

\author{
Asim Seedahmed Ali Osman' and Ahmed Seedahmed Ali Osman ${ }^{2}$ \\ ${ }^{1}$ College of Computing and Information Technology, Shaqra University, Kingdom of Saudi Arabia; \\ asalageed@su.edu.sa \\ ${ }^{2}$ Faculty of Computer Science and Information Technology, Al-Neelain University, \\ The Future University, Sudan; aalageed@neelain.edu.sd
}

\begin{abstract}
Objectives: Evaluating the performance of employees is one of the utmost requirements for the efficient functioning of higher educational institutions. In this article, we have developed automated task management system that can help higher educational institutions (like universities) to evaluate the performance of an employee (whether faculty member or staff). Method/Statistical Analysis: The system helps the managers in order to assess/identify the faculty member/ staff, employee and the colleges by the number of assigned task, the number of finished task and number of task which is late/incomplete. Findings: The proposed approach has been tested in one of the higher educational institutions i.e. Shaqra University. The sample size of user's includes 237 from different departments and the system provided performance evaluation of each individual employee in terms of task completion. Application: This methodology is proposed to apply among the employees working in the in Shaqra University as it is one of the higher educational institutions in order to evaluate their performance.
\end{abstract}

Keywords: Collaboration, Information Systems, Shaqra University, Task Management, Top Management

\section{Introduction}

The main aim of this Task management is to support the collaboration of remote or face to-face tasks given to the employees. It is the key component for managing all kinds of activities done in organizations. The main role of the task management is it can make the task more purposeful, threaded and reflective ${ }^{1}$. But, the efficiency of the task management remains under the increasing level due to the problems with in the team's communication. Various tasks are failed by meeting their goals due to the budget exceeding are also caused due to the failure in task management. A survey based the practices carried for task management in ${ }^{2}$ states that some of the important aspects of an outcome of the task include a face to face communication platform, monitoring it in an effective way etc.
The goal can be easily achieved in different dimensions with respect to the time, place and the availability of resources present in the organizations. Various examples proposed by researchers in ${ }^{3,4}$ are there for explaining how the task management is applied in organizations ${ }^{5,6}$, research and development software designetc ${ }^{7}$. In this study, the task management system is proposed in order to support the members of top management, deans of colleges, directors of various administrations and departments involving in the administrative decisions at Shaqra University. It can also be used as an evaluating tool for the employee based on the tasks assigned to them. Shaqra University is one of the new universities in the kingdom of Saudi Arabia. It's located in the middle of the kingdom and its one of the biggest university in the Arabic gulf region in terms of geographic area. The university has 
nine branch campuses within the central region of the kingdom. The university consists of twenty four faculties and ten deanships. The colleges are distributed over nine cities, each college and faculty has many departments and units, and any department has many faculty member and employee.

In general, the top management in the university assigns various tasks or projects to the deans of the faculties or deans of deanships in various colleges. The dean then assigns this respective task to the units or departments or he himself can create his own tasks. Also, the head of department or unit can also forward this task or projects to the faculty members or employee to perform it or he can create his own task and assign it to the staff in his department. The top management, the deans and the head of department need to follow the tasks and projects which ate already distributed in these branches since they want to know which is project or tasks is completed, which one of the given projects are delayed and which tasks are under process. In addition to the following advantages, if the managers need to measure the performance of the deanships and departments, faculty members and employees, they can use this task management system. The members who were active in this task management system are as follows, Top management (His Excellency the director, and vice directors), Deans of colleges and deanships, Directors of administrations and departments, teaching staff and employees.

The contribution of this article is listed as follows

- An automatic and scalable system that evaluates the performance of employees with less time complexity.

- Email notification feature with multi-file format support like (ppt, pdf, doc...).

\section{Objectives of the Proposed System:}

- To reduce the time and effort exerted in achieving tasks and projects.

- To provide the administration with statistical reports that assist in measuring the performance.

- To reduce the cost resulted from the lack of information.

- To computerize administrative tasks and to reduce the use of paper at university.

- To increase performance effectiveness and to measure performance indicators.
- To get reports in the appropriate time with the least cost and effort.

- To develop performance and to support university in its orientation towards electronic administration.

The developed system can access them to make sure the efficiency of various deanships and departments at university by obtaining detailed reports which illustrates the achievements of each department during a certain period of time, as well as its overdue for the assigned tasks and projects. This system also serves the deans of colleges and deanships and administrations directors in measuring the efficiency of the employees and teaching staff through evaluating their duties and achievements during the academic year.

\section{Literature Survey}

Various research works has been done in recent decades on this task management system. Many tools and methodologies have been developed and implemented to support each aspects of the task management system. This section depicts some of the tools proposed by earlier researchers for supporting task management strategies such as Trello, Slack, Asana, Todoist and Teamwork. These can be applied especially for every type of collaboration. It can be in the form of either face-to-face or within the teams which is present inside an organization. This section depicts various related works done on the task management methods practiced by the staff member's working in an organization. A citation analysis for faculty from Association of Collegiate Schools of planning member in schools is proposed in. This paper proposes that the Google Scholar data based data is a particularly valuable source foe the process of citation since its coverage extends beyond traditional publications which are peerreviewed in nature. Their analysis reports various level of scholarly based activity within the higher education institutions. The results show citation patterns for faculty, departments, and universities.

In proposed a novel comprehensive approach for evaluating the teaching performance based on the combination of two methods called as the fuzzy AHP and fuzzy comprehensive based evaluation method. They proposed this algorithm especially, after determining the factors and sub-factors present in the teaching. In their proposed system, initially the weights for factor and sub-factor are 
calculated by the fuzzy AHP method based on extent analysis. Applying the fuzzy AHP method of decision-making can improve the overall topology of the decision-makers by further reducing the uncertainty. In their system, the overall evaluation method is used to calculate the performance of teaching. A case study based application is also applied in order to express the proposed methodology. By this, it can make the overall calculation or estimating process more accurate and scientific without any kind of errors.

Various software and tools have been proposed by recent researchers for the efficient application of the task management in order to support the team collaboration. Various tools such as management of knowledge, management of coordination, information and communication exchange between the employees. An online based task and project management tool called as Trello ${ }^{8}$ provides various features in order to use it collaboratively. Various features such as notifications panel, calendar panel, comment window, file manager etc. where present in it. It can be used individually or for the teams. All the users who are utilizing it can perform the following operations such as creating sets of checklists, addition of labels, inviting people to join in various tasks and operations, and also connecting with various other applications.

A cloud-based open collaboration tool for team communication is Slack ${ }^{9}$ which gives a channel to organize the conversations between teams involved in a project. A transparency in the teamwork as well as a channel for sharing the sensitive information is provided in this tool. Various features such as sending direct messages, sharing of files, passing comments, placing stars for the purpose of later reference, connection and integration with other services, etc. where available. All the files which are present in it are archived automatically and it can also be synchronized automatically towards different devices. Another personal task management too ${ }^{10}$ is an in build tool with consists of various features such as performing the tasks and projects, combining it with various conversations. A quick view of a particular team updates and tasks without being scheduling different meetings and at a glance is proposed on this tool. Features such as the creation of tasks and projects, setting the due dates and times for the projects etc. Also, some advanced features such as the use of special symbols in order to encourage the members who participated in the activity, tasks completion, file management, searching, calendars, dashboards for verifying the status of the overall progress or its com- pletion, a mailbox for automatic updates, management of features with the team, followers and combination with other software tools etc.

A task manager called Todoist ${ }^{11}$ is designed for using $n$ different devices for the purpose of collaborative productivity in the entities and also for the purpose of maintaining lists which is present in different devices. Different online or offline functions such assetting and managing the tasks within the teams can be done using this task management tool. And, it can be done in different platforms. It is also used for collaborating shared tasks with other task management tools in real time for the process of customizing the experience of an end user. Some basic and advanced features such as notification manager, synchronization and managing the real-time data, productivity visualization, comments about the tools, filters etc. where supported by this tool. At last, an online platform for project management which is called as Teamwork ${ }^{12}$ is proposed for the process of supporting different features such as time management and logs in order to keep in touch about the processing time taken for completing a task, It also monitors the overall member present in the team, view of the tasks, re assigning the task to other member etc.

\section{Proposed Methodology}

In general, there are many methodologies used for software development. In this paper, an incremental build model as shown in Figure 1 is used in order to implemented and tested incrementally i.e., additional tasks can be added at each time until all the tasks are done in order to complete the overall product. The incremental model involves both the stages of development and maintenance.

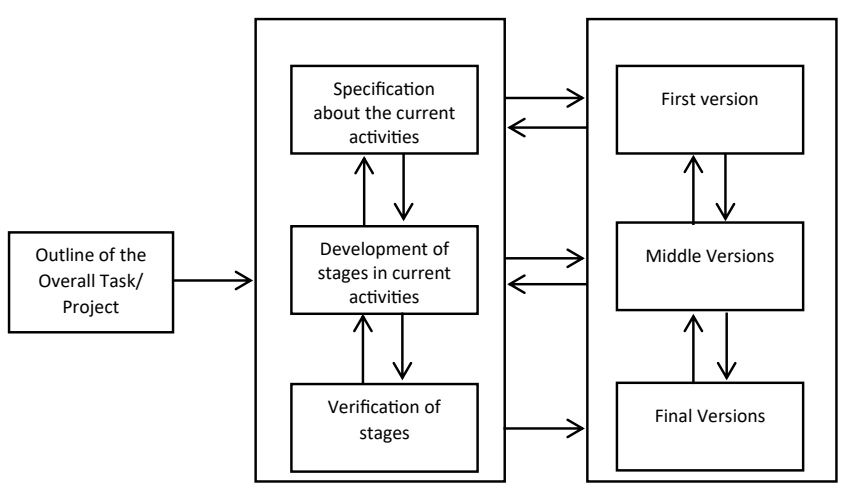

Figure 1. Architecture of the Incremental model used in this methodology. 
The product is concluded as finished when it satisfies all of its requirements.

The main goal of this project is to reduce the gap between the high level manager in the university who is the rector or a vice rector and the colleges and deanships. It also reduces the gap between the deans of the colleges and their respective faculty members or employees. This also provides a simple interface to manage the various project \& tasks assigned to the employees. In this system, the components are divided depends on the user privileges. In this method, the programmer will design, implement and test all the components and then it is further given it to the customer side. The, the customer can use it accordingly. In this work, initially the author developed the component for various departments, then the faculty member and staffs respectively. Then, they used it when the next component which is manager is in developing stage, and at last, the high manager component is developed and integrated with other components and further, it is tested as a whole system.

This task management system is developed to provide four privileges process which is present the work structure of an university as shown in use case diagram in
Figure 2 which shows the various functions for an actor in the system and what he does in it.

\subsection{Use Case Diagram}

The use case diagram shown in Figure 2 has five actors. First actor is the high level manager. $\mathrm{He}(\mathrm{He} / \mathrm{She})$ can login into the system and can add the colleges and Deanships in it. He can also add the staffs or employees. He can also create the task and assign it to various deanship, colleges or staff. He can also check the performance of deanships, colleges or departments and also the staff members working in it. He can divided one project to small tasks. He has the privilege to follow, delete, cancel and edit any tasks which are assigned to the individual staff members. He can also change the status of task, can write a comment or add attachment file.

The second actor is manager or dean. Firstly he should login to the system. Then he can create the departments and units in his college or deanship. After this, he can add faculty staff member or employee, can create and assign various task to the respective departments or staffs, can forward the task which is created already and assign it

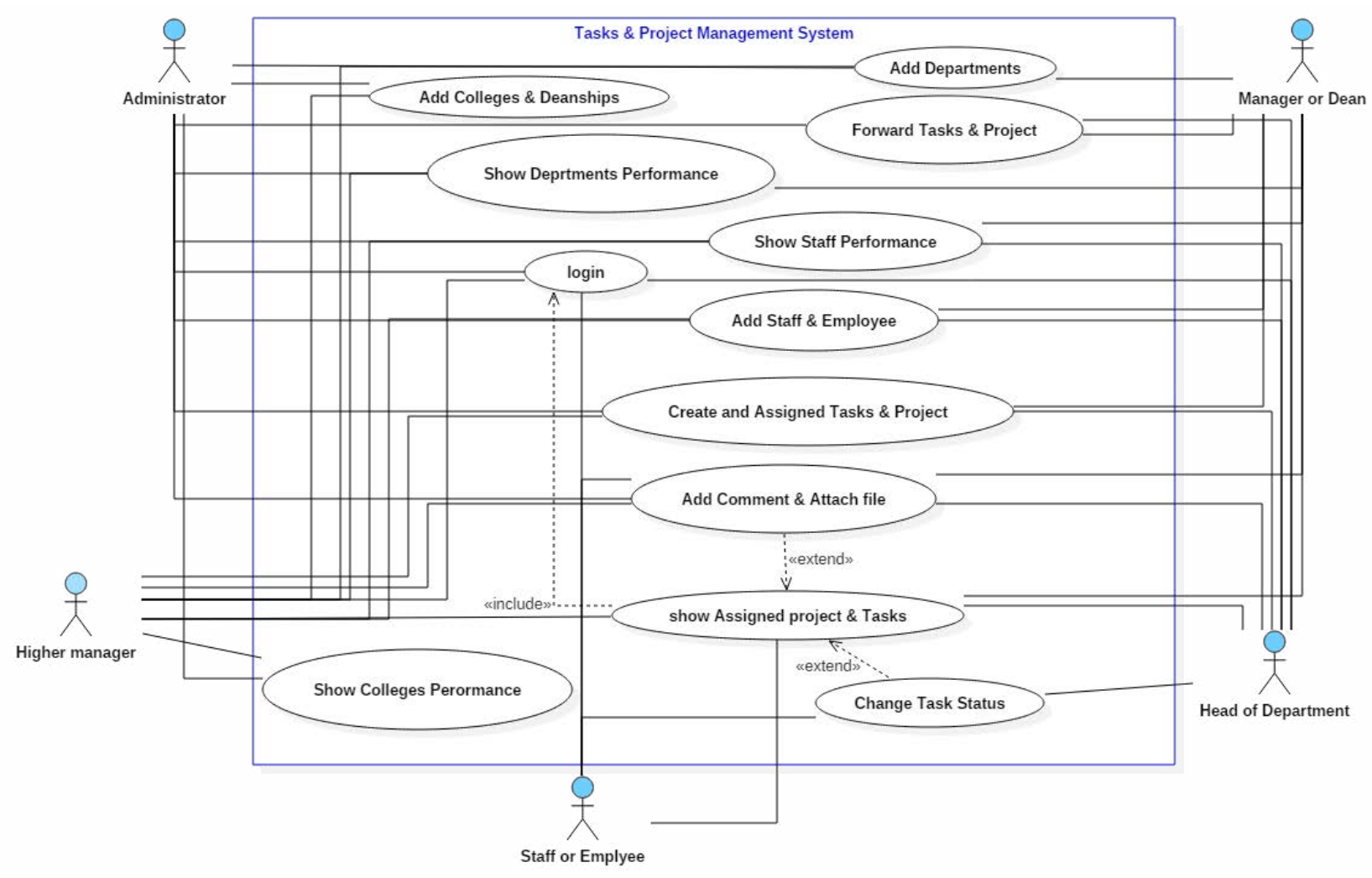

Figure 2. Use case diagram of the proposed methodology. 
to the respective departments or staff, can edit, delete or cancel the tasks, can show the performance of his department/staff, can write a comment or attach files to tasks and finally, he can divide the project in to many tasks. Third actor is the head of department or unit. Initially, he should login to the system. Then, the system will allow him to add faculty/staff members and employees to his department or unit, he can create tasks and assign it to his staffs, can forward the task to his staffs, can add comments and attach files, can change the status of task, can show the performance of his faculty/staff member sand employees, can edit or delete or cancel the tasks he was created, finally he can divide the project to many tasks.

The fourth actor is faculty member or employee. Initially, he should login to the system. Then, after the login activity, he can see the tasks assigned to him and it's further divided to four sections as shown in the Figure 3. In this figure, new tasks and project are represented in blue color, the tasks and projects which are under process are represented in orange color, finished tasks are represented as green in color, delayed tasks and projects are represented in red color. He can see the details of tasks, can add comments or attach files, he can change the status of tasks from new to under process and then to finished stages. Last actor is the administrator of the system he can do all the above mentioned functions in the system.

\section{Findings and Discussion}

The main interface window of high level manager is shown in Figure 3. This is an overall statistical performance report for all colleges and deanships. This report shows the number of overall tasks for the colleges. In this, the number of new tasks in the colleges or deanships is shown in blue color. It shows the number of finished tasks and project in the colleges or deanships. It also shows the delayed project and tasks in the colleges or deanships.

The statistical report is same for manager but for it will be for his departments only. The system allows the manager to forward the task which came from the high level manager.

Figure 4 shows the interface window of the faculty member staff when he login to the system. This window can be divided in to four sections depending on status of task which are new, under process, finished, cancelled. He can verify the details of the task after he opens any of the new tasks assigned to him. At once, the status of the task will change automatically towards under process. He can add any comments or attach files which can be pdf, word, power point...etc. and after he completed the tasks, he can change the status of task to finished state.

Figure 5 is the report provided by the system for helping the managers in order to assess/identify the faculty

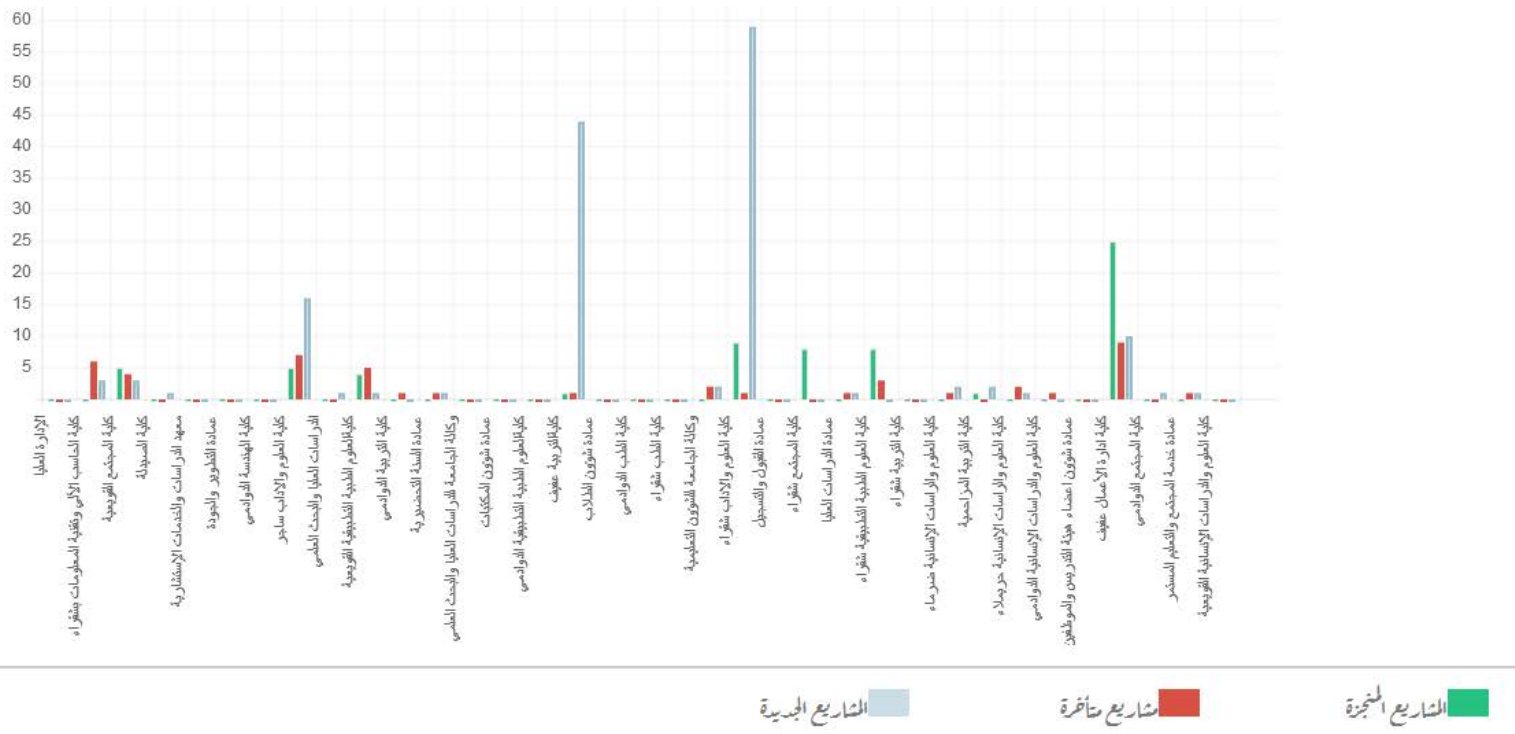

Figure 3. User Interface of the proposed Task Management tool. 


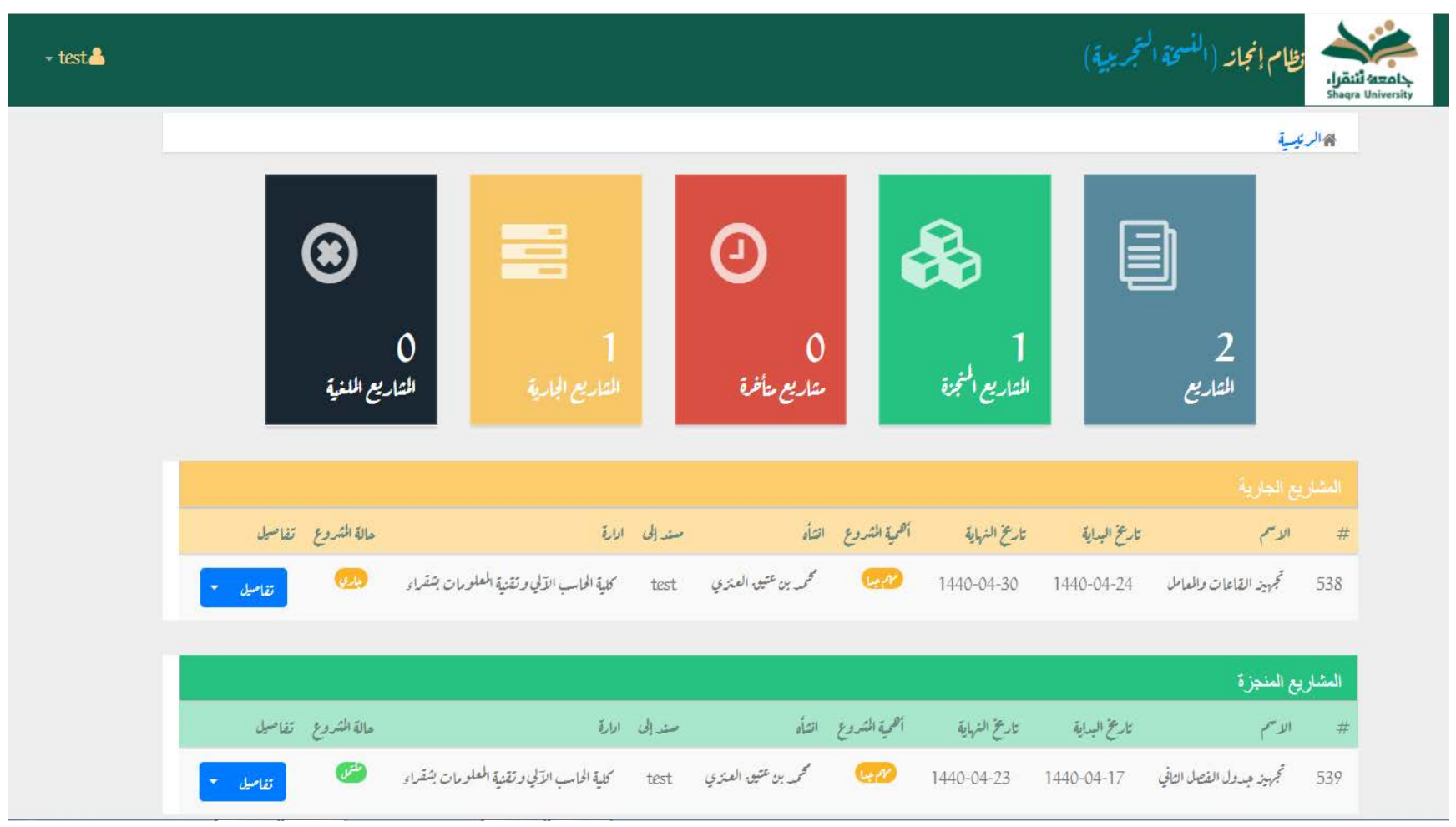

Figure 4. User Interface for Faculty member after logging in.

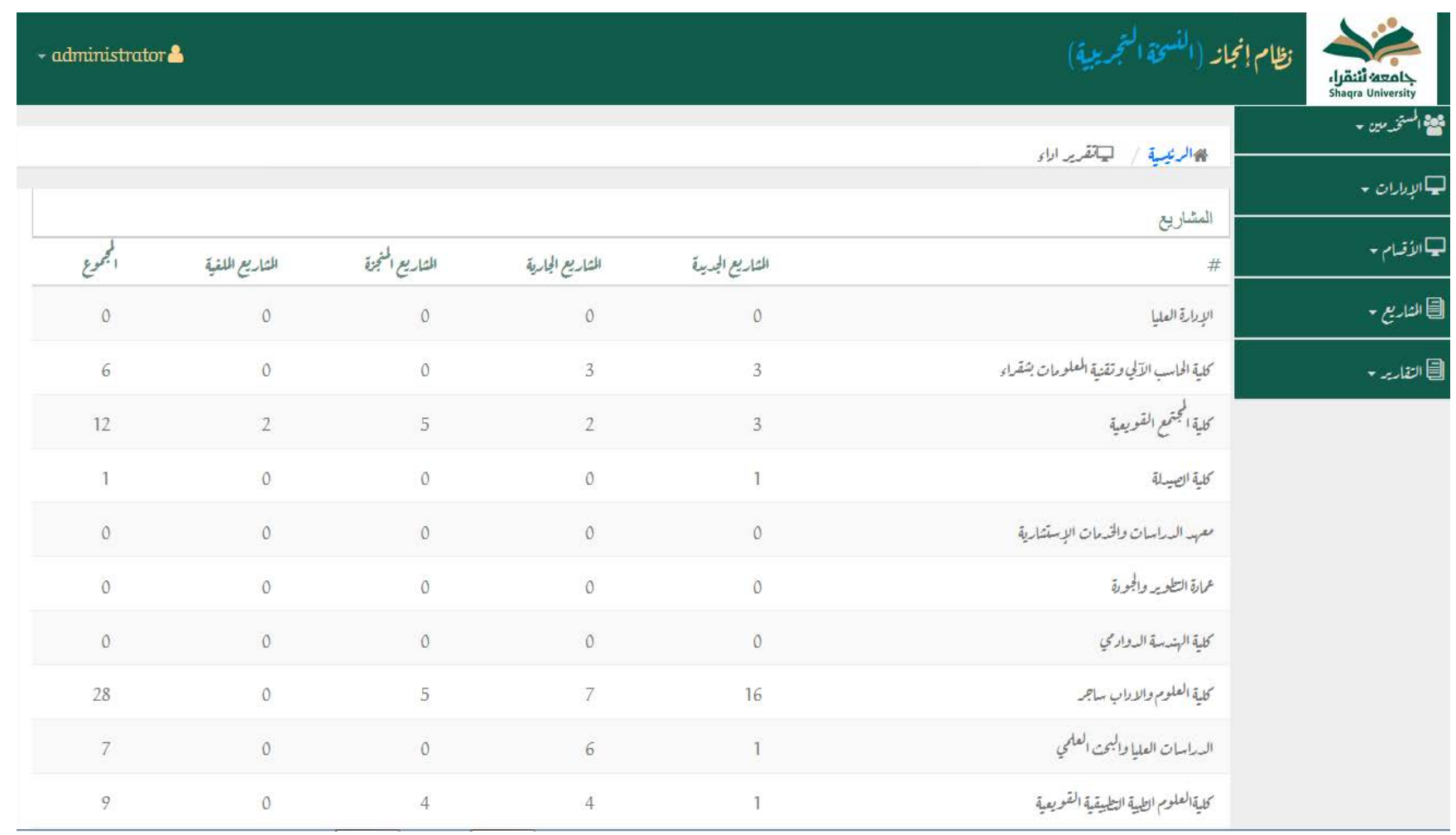

Figure 5. Report generated fort the completed tasks for individual members. 
member/staff, employee and the colleges by the number of assigned task, the number of finished task and number of task which is late/incomplete.

\section{Experimentation (A Case Study of Shaqra University)}

\subsection{Data Collection}

All the data were collected by interview method by interviewing the four level of the system. It is done by asking them why you need the task management system, what is the type of report you need it from the system? The data collected is shown in Table 1 which has the details about number of peoples they interviewed and the type of users who were involved in the interview.

Implementation results for the proposed system in Shaqra University along with the total number of such users are shown in Table 2. It consists of the deanships and colleges who used the system in Shaqra University, departments and units in the system, different user's privileges in the system, existing projects and tasks present in the system and the new projects and tasks that are coming to this system.

Table 1. Details about number and types of peoples involved in the interview

\begin{tabular}{|l|l|}
\hline Type of user & $\begin{array}{l}\text { Total } \\
\text { Number }\end{array}$ \\
\hline High level manager ( Rector, Vice Rector) & 2 \\
\hline Managers (Dean of the colleges and Deanships) & 4 \\
\hline Head of departments and units & 8 \\
\hline Faculty members staffs and employees & 12 \\
\hline
\end{tabular}

Table 2. Implementation results for the proposed system

\begin{tabular}{|l|l|l|}
\hline Sl.No & $\begin{array}{l}\text { Implementation results for the proposed } \\
\text { system }\end{array}$ & Count \\
\hline 1 & $\begin{array}{l}\text { Deanships and colleges who used the } \\
\text { system }\end{array}$ & 35 \\
\hline 2 & Departments and units in the system & 70 \\
\hline 3 & Different users privileges in the system & 237 \\
\hline 4 & $\begin{array}{l}\text { Existing Projects and tasks present in the } \\
\text { system }\end{array}$ & 473 \\
\hline 5 & $\begin{array}{l}\text { New project and Tasks coming to this } \\
\text { system }\end{array}$ & 111 \\
\hline
\end{tabular}

\section{Conclusion}

This study proposes a novel methodology of task management in Shaqra University to enable effective team collaboration. This study has aimed to to meet the important business objectives such as improving competitiveness, increasing productivity and efficiency, accelerating growth, supporting innovation and reducing costs within an organization. A complete idea about the methodology, various stages of the system and an analysis which is used for assuring the adaptability of the system in the Shaqra University is explained. The study has aimed to improve the practice of collaboration between the teams of employees and the employers. Using this too improves various work-related activities, monitoring the activities, team collaboration, etc. The results have helped the high level managers to find the flow of work done and the time taken to complete task delivered to the employees. It also enables the collaboration of employees in the process of increasing productivity and efficiency. Future work can be the proposal of a task management tool for collaborating more departments for various interacting processes within teams.

\section{References}

1. Bellotti V, Bly S. Walking away from the desktop computer: Distributed collaboration and mobility in a product design team. Proceedings of the 1996 ACM Conference on Computer-supported Cooperative Work ACM. 1996. https://doi.org/10.1145/240080.240256

2. Eppler MJ, Sukowski O. Managing team knowledge: Core processes, tools and enabling factors. European Management Journal. 2000; 18(3):334-41. https://doi. org/10.1016/S0263-2373(00)00015-3

3. Garrison DR. Online collaboration principles. Journal of Asynchronous Learning Networks. 2006; 10(1):25-34.

4. Holton JA. Building trust and collaboration in a virtual team. Team Performance Management: An International Journal. 2001; 7(3/4):36-47. https://doi. org/10.1108/13527590110395621

5. Lanubile F. Collaboration tools for global software engineering. IEEE Software. 2010; 27(2):52-5. https://doi. org/10.1109/MS.2010.39

6. Meredith JR, Mantel Jr. SJ. Project management: A managerial approach. John Wiley \& Sons. 2011.

7. Ocker RJ, Yaverbaum GJ. Asynchronous computer-mediated communication versus face-to-face collaboration: 
Results on student learning, quality and satisfaction. Group Decision and Negotiation. 1999; 8(5):427-40. https://doi. org/10.1023/A:1008621827601

8. Tutty JI, Klein JD. Computer-mediated instruction: A comparison of online and face-to-face collaboration. Educational Technology Research and Development. 2008; 56(2):101-24. https://doi.org/10.1007/s11423-007-9050-9

9. Wasser JD. Bresler L. Working in the interpretive zone: Conceptualizing collaboration in qualitative research teams. Educational Researcher. 1996; 25(5):5-15. https:// doi.org/10.3102/0013189X025005005
10. White D. Fortune J. Current practice in project management - an empirical study. International Journal of Project Management. 2002; 20(1):1-11.

11. Sanchez TW. Faculty Performance Evaluation Using Citation Analysis: An Update. Journal of Planning Education and Research. 2017; 37(1):83-94. https://doi. org/10.1177/0739456X16633500

12. Chena JF, Hsieha HN, Do QH. Evaluating teaching performance based on fuzzy AHP and comprehensive evaluation approach. Applied Soft Computing. 2015; 28:100-8. https:// doi.org/10.1016/j.asoc.2014.11.050 